\title{
De la oportunidad reglada a la Mediación. Una progresión ineludible para el reposicionamiento de la víctima en el proceso penal cubano
}

\section{From the opportunity regulated to the mediation. An Inescapable progression for the repositioning of the victim in the Cuban penal process}

\author{
Arnulfo Sánchez García \\ Universidad Autónoma de Nuevo León, México \\ arnulfosanchezgarcia@hotmail.com \\ Yulisán Fernández Silva \\ Universidad Autónoma de Nuevo León, México \\ fedezyulisan@gmail.com
}

Recibido: 14 de diciembre de 2018 / Aceptado: 05 de mayo de 2019 https://doi.org/10.17081/just.24.36.3764

\section{Resumen}

El artículo presenta un bosquejo de la situación actual de la víctima en el proceso penal cubano, y los aspectos que inciden en su exclusión y vulnerabilidad. Desde esa perspectiva, se evalúan los componentes de la Mediación, que favorecerían su retorno como sujeto procesal, y una mayor eficacia en la reparación del daño. Se analiza el ejercicio de discrecionalidad que ostenta el Ministerio Público y la factibilidad de establecer un esquema progresivo que opere en función de la aplicación de criterios de oportunidad hacia derivación de casos a Mediación. Finalmente se identifican las tipologías delictivas en las resulta más factible un abordaje desde esta vía no adversarial.

Palabras Clave: mediación; víctima; proceso penal; reparación; ministerio público

\section{Abstract}

The article presents an outline of the current situation of the victim in the Cuban criminal process, and the aspects that affect their exclusion and vulnerability. From that perspective, the components of the Mediation are evaluated, which would favor their return as a procedural subject, and a greater effectiveness in repairing the damage. The exercise of discretion analyzed by the Public Prosecutor's Office and the feasibility of establishing a progressive scheme that operates based on the application of opportunity criteria towards referral to Mediation cases are analyzed. Finally, criminal typologies are identified in which an approach from this non-adversarial route is more feasible.

Keywords: mediation; victim; criminal procedure; reparation; public ministry

\section{Como citar:}

Sánchez García, A., \& Fernández Silva, Y. (2019). De la oportunidad reglada a la Mediación. Una progresión ineludible para el reposicionamiento de la víctima en el proceso penal cubano. Justicia, 24(36), 177-195. https://doi.org/10.17081/just.24.36.3764

Justicia Vol. 24 No. 36: pp. 177-195. Julio - diciembre, 2019. DOI: 10.17081/just.24.36.3764 (C) Copyright 2019 by Sánchez García, A \& Fernández Silva, Y

open 2 access (c) (i) 


\section{INTRODUCCIÓN.}

El contexto actual del entramado jurídico penal cubano aún postula la interacción dos Sistema Procesales tradicionalmente antagónicos. La fase indagatoria del proceso criminal mantiene la preeminencia del modelo Inquisitivo, con cierta restricción de garantías a los involucrados en el conflicto; sin embargo, el diseño acusatorio instaurado en la etapa de juicio oral proyecta un reforzamiento en los derechos de los contendientes, en consonancia con el perfil adversarial que impone su configuración.

Este esquema instrumental, ha determinado que la víctima mantenga una postura marginada como sujeto procesal reduciendo su intervención a la condición de testigo, situación que determina su aislamiento y entorno vulnerable dentro del proceso investigativo; además de alejarse la posibilidad real de una reparación expedita y eficaz.

A finales de la década de los setentas del pasado siglo, se realizaron modificaciones tanto en la Ley procesal como en la sustantiva que sobrevinieron de la necesaria institucionalización del país. Estas transformaciones continuaron a medida que requirió actualización y perfeccionamiento el modelo económico y su incidencia en el Sistema de Justicia.

La década de los ochentas constituyó una "etapa prodigiosa" (Rivero, 2010, p. 46), dentro de la promulgación de normas garantistas y la implementación de criterios de oportunidad desde la persecución penal. Sin embargo, con el derrumbe del bloque socialista, y el crecimiento de las sanciones económicas del Gobierno de Estados Unidos hacia la Isla; sobrevino un nuevo escenario caracterizado por el aumento de eventos delictivos de gran repercusión social.

Estos vaivenes en la esfera social, motivaron algunas modificaciones en la normativa criminal, que en su conjunto provocaron una antinomia entre la despenalización de algunas conductas delictivas ya inoperantes, y el incremento de la severidad de algunas sanciones, en virtud de ilícitos penales que comenzaban a ejecutarse con gran frecuencia.

No obstante, en los últimos años se han promulgado modificaciones en el ámbito sustantivo y procesal con vistas a descongestionar el aparato judicial y reducir la duración de los procesos. Todo ello ha sido posible a partir de la flexibilización y extensión del catálogo de delitos elegibles, en función de la aplicación de los criterios de oportunidad en la legislación sustantiva. Sin embargo, en la práctica jurídica cubana el delito se sigue visualizando desde una perspectiva adversarial, donde la condena es proporcional a la afectación del bien jurídico protegido por la norma.

Por otro lado, la víctima sigue pendiente de reivindicación y reposicionamiento como sujeto determinante en la solución del conflicto penal; su reparación en la actualidad transita por un período de insatisfacciones, y compensaciones aplazadas ante la insolvencia de la entidad que gestiona la indemnización. Se trata pues, de un status quo donde no se ha brindado la posibilidad de empoderamiento a los sujetos que sufren directamente los efectos de la comisión del hecho delictivo. Por lo que, el escenario impone una reanálisis del discurso sobre la eficacia del Sistema tradicional adversarial; $y$ 
la pertinencia de nuevos instrumentos legales que armonicen alternativas razonables con arreglo a la optimización del Modelo vigente.

En este sentido, la mediación representa una vía oportuna de resolución de controversias, que puede contribuir a reinsertar al perjudicado a su indiscutible papel protagónico; estimando que el ordenamiento jurídico actual prevé fórmulas no adversariales que articulan el esquema de potestades concedidas al órgano rector de la procuración de justicia.

En virtud de ello, la investigación ilustra sobre las afectaciones que sufren las personas perjudicadas por la comisión de delitos en el cauce del proceso penal, contexto en el que la instrumentación de la Mediación contribuiría a la eliminación de estas contingencias, en favor del reposicionamiento de la víctima. Así mismo, se identifican las tipologías delictivas en las que resulta más factible la aplicación de los criterios de oportunidad, a partir del margen de discrecionalidad que se le concede al Ministerio Público para evaluar y determinar la derivación de casos a vías no judiciales.

Es válido señalar, que con el abordaje científico de este artículo no se pretende absolutizar en la Mediación como único agente de influencia en la restitución del ofendido por la representación del conflicto penal desde la misma fase indagatoria. Otros instrumentos pacíficos y resolutivos podrían resultar de significativa utilidad como la conciliación y la negociación. En ese orden de ideas, la razón de decantarse por la mediación obedece a que le otorga mayor relevancia a la autogestión y capacidad resolutiva de las partes a través de la gestión del mediador; lo que en definitiva disminuye el tiempo empleado.

\section{TRATAMIENTO A LA VÍCTIMA EN EL ORDENAMIENTO JURÍDICO PENAL ACTUAL}

El modelo jurídico cubano no ha estado ajeno a las corrientes contemporáneas, que tienen en la etapa de la colonización su principal antecedente. En este período, la metrópoli española introdujo notorios instrumentos jurídicos a través de la administración peninsular, que estampó una etapa luminosa en el Derecho Procesal de la Isla. Sin embargo, el aislamiento de la víctima en las legislaciones extensivas al entorno caribeño sería la nota distintiva que trascendería hasta las normativas vigentes.

La Ley No.5 de Procedimiento Penal (LPP) vigente desde 1977, mantuvo los postulados de sus predecesoras (Rivero, 2010, p.42), a comentar la Ley de Enjuiciamiento Criminal española, de 14 de septiembre del 1882, hecha extensiva a Cuba y Puerto Rico y que comenzaría a regir el 1 ro de enero de 1889 , al mismo tiempo en que fungiría las audiencias de lo criminal en la Isla (Bodes, 1988, p.30) y la Ley Procesal No. 1251 de 1973.

La normativa introdujo un nuevo arquetipo procesal al segregar en varias instituciones pertenecientes al poder público las funciones de investigación, ejercicio de la acción penal y juzgamiento. El instrumento legal estuvo vigente por ochenta y cuatro años, y aunque fue objeto de algunas modificaciones, estas no fueron enfocadas a resposicionar a la víctima en el proceso, sino a reforzar los derechos de su contraparte, el acusado, en función de ofrecerle nuevas vías en el ejercico de su defensa (Rivero, 2014, p.3). 
En su estructura orgánica propugna un diseño jurídico binomial con preponderancia del sistema inquisitivo en la fase indagatoria, y el monopolio del Ministerio Público en la persecución penal. Una segunda etapa con predominio del sistema acusatorio centra sus fundamentos en la identificación de las partes dentro del debate penal en el acto del juicio oral. El juez dirime el conflicto penal a través de la libre apreciación del material probatorio en función de la búsqueda de la verdad histórica (Rivero, 2010, p. 38).

Llama la atención en este cuerpo legal el contenido normativo del art. 109 que reconoce con carácter general la protección de los derechos de la víctima, los que preceptivamente deberán ser salvaguardados por el Ministerio Público. Luego, en los subsiguientes artículos del texto procesal, la víctima mantendrá un estatus relegado a la condición de testigo:

ARTícUlO 109. (Responsabilidad del Fiscal.)Durante la tramitación de la fase preparatoria el Fiscal, además, supervisará el cumplimiento de la Ley en la ejecución de las acciones, diligencias y trámites así como en la calificación legal de los hechos; seguirá el curso de la instrucción y cuando resulte necesario, dispondrá la práctica de acciones y diligencias indispensables para la comprobación del delito, la determinación del autor y demás circunstancias esenciales, o las realizará por sí mismo; y velará por el respeto de las garantías procesales del acusado, por la protección de los derechos de la víctima o perjudicado por el delito y por los intereses del Estado y de la sociedad.

Un elemento significativo de la lectura de este artículo, parte de reconocer el ejercicio de la acción en el proceso ordinario, como un presupuesto de apertura del juicio oral y límite a la jurisdicción, reservando la persecución punitiva exclusivamente al Fiscal. Por tanto, ni el ofendido ni el órgano jurisdiccional pueden adjudicarse estas funciones, salvo algunas excepciones, específicamente el capítulo de los "Delitos perseguibles a Instancia de Parte"; y el empleo de la fórmula del art. 350 que se aborda más adelante (Rivero 2012, pp.160-165).

Similar vertiente procesal devela el sobreseimiento injustificado del art. 268, como presupuesto de culminación del proceso. En el apartado se consigna que, en caso de estar concluido el expediente de fase preparatoria, si el Tribunal desestima la solicitud de sobreseimiento propuesta por el Fiscal, el perjudicado asume el ejercicio de la acción penal a través de un escrito de querella, con la condición de que la acción particular se ejecute en un plazo que no exceda los 10 días hábiles. En resumen, en este apartado la víctima se encuentra condicionada al desinterés del acusador público para ejercitar la acción penal.

La incorporación de la llamada "fórmula" prevista en el art. 350 de la legislación procesal cubana no es originaria de la normativa de la Isla, aunque sí ha tenido una incidencia importante en la causalidad de los eventos delictivos (Rivero, 2014, p.152). El apartado faculta al órgano judicial para a asumir el ejercicio de la acción penal bajo determinadas pautas, cuando no desee continuar con la imputación la Fiscalía (Rivero, 2012, p.230). 
La acción es transferida del Ministerio Público hacia el órgano jurisdiccional, que asume su ejercicio al estimar que existen elementos para suponer responsable al acusado en defensa del interés general y de no quedar impune el evento delictivo.

Lo anterior, solo aplica al interés social y no en favor de la víctima para investirse en acusador particular conforme al orden lógico de todo Sistema de Justicia penal garantista. Por el contrario, si la Sala de Instancia admite la retirada de acusación, inhabilita al perjudicado de cauce procesal para revertir esta decisión.

De manera similar, el art. 356 del mismo cuerpo legal dispone que en cada sesión de juicio oral el secretario extienda un acta, consignando en ella todo lo que ha ocurrido. Por solo mencionar un ejemplo, el documento puede contener la protesta de las partes si mostraron su inconformidad por alguna razón de procedibilidad o de inadmisión por algún elemento probatorio. Este derecho, se entiende solo a la Fiscalía y al acusado como partes; por el contrario, le está vedado al perjudicado ejercitarlo debido a su condición de testigo.

No obstante, existen algunos apartados que regulan el procedimiento especial por los Delitos Perseguibles a Instancia de Parte. Este acápite es el que otorga mayor interés a la intervención de la víctima. La Institución, aunque solo opera en los delitos de Injuria o Calumnia, le concede en los arts. 420 y 434, la facultad al ofendido de sostener la acusación, en asesoría de un representante legal. Estas tipologías delictivas ofrecen un mayor grado de independencia al perjudicado, toda vez que, si no se ejercita la acción penal por el particular, el Tribunal no podrá realizar su función de impartir de justicia.

Otro ejemplo de reconocimiento al perjudicado en el texto procesal lo constituye el capítulo de los Delitos contra el Honor. El precepto legal regula el actuar del ofendido en el ejercicio de perseguibilidad. Empero, esta faculta está limitada al establecer como requerimiento la presencia de un representante legal para sostener su pretensión.

En un matiz más inclusivo, la Ley de Procedimiento Penal Militar habilita un capítulo (III) para identificar los derechos y deberes de los participantes en el proceso; sección que reconoce a la víctima como sujeto procesal y condición de perjudicado en tanto haya sufrido algún daño moral, físico o patrimonial (Ley No. 6, 1977, p. 8):

ARTíCULO 35.- El perjudicado o su representante puede examinar la causa, proponer pruebas, formular peticiones y recurrir las actuaciones y resoluciones del investigador militar, el Instructor Fiscal, el Fiscal o el Tribunal.

Estas potestades son ratificadas ante el órgano jurisdiccional en el acto del juicio oral. (Ley No.6, 1977, p. 64)

ARTícULO 297.- El Fiscal, el acusado o su defensor, el tercero civil responsable $y$ el perjudicado, tienen en el juicio oral los mismos derechos para presentar pruebas, participar en la práctica de éstas y formular peticiones al Tribunal.

Justicia Vol. 24 No. 36: pp. 177-195. julio - diciembre, 2019. DOI: 10.17081/just.24.36.3764 
Indudablemente el procedimiento penal militar concede mayor relevancia y autonomía a la intervención de la víctima, al permitirle auto tutelarse sus derechos sin necesidad de un intérprete judicial.

A pesar de ello, la normativa mencionada aún está pendiente de perfeccionamiento toda vez que, utiliza indistintamente las categorías de víctima y perjudicado dentro de la narrativa del articulado, otorgando el debido reconocimiento solo al segundo.

Ello determina que la protección solo se destine a la persona que resultó afectada, la que no siempre coincide con la verdadera víctima del ilícito penal, que también en este orden procesal comparece como testigo (art.177). De modo que, solo el perjudicado puede acreditar una participación en el acto del juicio, sin que ello coincida con la persona que verdaderamente debe ser resarcido.

La legislación sustantiva también requiere ser examinada habida cuenta que tiene una incidencia importante tanto en fuero común como el castrense. El código penal, Ley No. 62 de 1987, mantiene la tradición normativa de su predecesora, aunque se han incorporado nuevos postulados con el propósito de descongestionar la labor de la judicatura en la impartición de justicia.

En ese sentido, cabe señalar que hay algunos atisbos dentro del cuerpo legal vigente, que denotan cierta protección a la víctima, aunque incipiente. La sección de la adecuación de la pena es un ejemplo de ello. En dicho capítulo se distinguen dentro de las circunstancias agravantes de la responsabilidad penal, la inclusión de algunas causales que determinan la agravación de la pena cuando del hecho acaecido existe relación marital, de parentesco o amistad entre víctima y agresor; y además, en situación de indefensión con relación al ofensor (Rivero \& Bertot, 2017, p.69).

La misma normativa, en el artículo 142 configura el tipo penal de Atentado, dentro del Título Delitos contra la administración y la Jurisdicción; y aborda en su tercer apartado una protección genérica a los familiares de la persona que ha comparecido al proceso en condición de víctima o testigo.

También la configuración legal del delito de Incumplimiento de las obligaciones derivadas de las contravenciones previsto en el Apartado 170 del Código Penal, contiene como requisito de procedibilidad, la denuncia del funcionario que emitió la resolución. El injusto penal tiene como nota distintiva, que la condición de perjudicado recae en el órgano estatal que fue asignado a la Oficina de Control y Cobro de multas a partir de la promulgación de la Instrucción No. 190 del 11 de febrero del 2009 del Consejo de Gobierno del Tribunal Supremo Popular (Gómez, 2010, p. 41).

Similar requerimiento, se observa en el ilícito de Daños (art. 179.3), otorgando la posibilidad inclusive de archivar las actuaciones si la víctima desiste de la denuncia antes del juicio oral.

Igualmente, en los delitos cometidos en ocasión del tránsito ferroviario, aéreo o marítimo (art.184.1.2), la figura de Apropiación Indebida (art.335.4) y el delito Estafa (art.334.5); se les concede la posibilidad de rescindir la acción antes del juicio oral, si el 
acusado abona la cantidad sustraída mediante cheque como forma de pago al denunciante (Ley No 62, 1987).

Por otro lado, la sección que contiene los "Delitos contra el normal desarrollo de las relaciones sexuales", se establecen regulaciones complementarias que disponen en los casos de Pederastia con Violencia, Violación, Bigamia, Incesto, Abusos lascivos y Matrimonio ilegal, es indispensable la formalización de la denuncia por la persona agraviada a sus parientes consanguíneos, cónyuge, o representante legal; con excepción del hecho que haya revelado alarma requiriendo el ejercicio de la acción penal por el Ministerio Público (Ley No 62, 1987, art. 309).

En contraposición, hay otros apartados que sumergen a la víctima en un irremediable desamparo. El numeral 8 del capítulo uno, referente al concepto de delito, integra dos apartados por los cuales se habilita una vía en razón, de criterios de oportunidad, para desestimar la vía jurisdiccional como solución al conflicto penal; la que hoy resulta un verdadero escollo en la legitimación y reconocimiento de ofendido (Rivero \& Bertot, 2017, p.7).

La decisión de elegir una u otra variante opera en función de categorías condicionantes -peligrosidad social del hecho, y condiciones personales del autor-para la derivación de casos priorizando la reparación del daño. Esta facultad es exclusiva de órgano judicial o el Ministerio Público en razón de un interés general, lo que destina a la víctima al designio pautas ya establecidas que en exiguas ocasiones coinciden con su verdadera afectación.

No obstante, el tema que ocupa más atención en la actualidad por la sensibilidad e insatisfacción que provoca en los ciudadanos que son víctimas de hechos delitivos, es la ejecución de la responsabilidad civil derivada del delito.

La problemática debe ser analizada desde dos matices que inciden en la complejidad de una solución eficaz: el desarraigo de la configuración legal de la Institución en pos de la legislación civil, y la incapacidad de la Caja de Resarcimientos como órgano gestor en la asistencia económica a los perjudicados.

Una peculiaridad de la Ley sustantiva vigente que le distingue de instrumentos jurídicos predecesores, es la inclusión en el art. 70 como aspecto novedoso y controversial, de la declaración y extención de la resposabilidad civil por el Tribunal de Instancia conforme a lo que rige en la legislación civil. ${ }^{1}$

Este aspecto, suscitó comentarios favorables por la unificación jurídica en el tópico de las obligaciones civiles derivadas de la comisión hechos delicitivos. Sin embargo la práctica jurídica ha revelado un antinomía debido a que la remisión externa y genérica a la legislación civil no define ni explicita el itinerario procedimental; por lo que solo constituye un juicio de inferencia hacia la norma sustantiva, máxime cuando la vía civil aún adolece de resortes eficaces en la ejecución de sentencias (Goite \& Méndez, 2014, p.299)

${ }^{1}$ El Código de Defensa Social, y la Ley 21 de 1979, disponen en su configuración legal, un cauce jurídico que determina la declaración y la extensión de la responsabilidad civil derivada del delito, bajo la égida del Derecho Penal.

Justicia Vol. 24 No. 36: pp. 177-195. julio - diciembre, 2019. DOI: 10.17081/just.24.36.3764 
Otro tema aún mas preocupante, es la gestión de la reparación de la víctima por entidad encargada hacer efectiva dicha compensación. La Caja de Resarcimientos, Institución encargada de asistir económicamente a las víctimas de delito, inició su funcionamiento en 1939, como entidad gestora y unidad ejecutiva, de la normativa que reglaba la responsabilidad civil proveniente del delito: el Código de Defensa Social. Inicialmente esta Institución estuvo adscripta al Ministerio de Hacienda, hasta que en el año 1953 pasó a formar parte del Ministerio de Justicia. La Ley Decreto 1258 de enero de 1954, es el instrumento jurídico que regula su funcionamiento (Gómez, 2010, p. 47).

Como nota distintiva de este ordenamiento hay que señalar su longevidad, con más de seis décadas de funcionamiento y una configuración legal que no responde al contexto actual. Este escenario ha constituido un lastre, en la sistematicidad de ejecución de pagos por parte del órgano gestor. Su diseño normativo carente de virtualidad ha tenido que ser modificado en dos ocasiones para atemperarlo a la dinámica actual del Sistema de Justicia.

La primera modificación se realiza en el año 1959 con la instauración del nuevo sistema de gobierno, mediante la promulgación la Ley No.597 de fecha 7 de octubre del propio año. El cuerpo legal introduce cambios esencialmente estructurales y de glosario jurídico, que permiten acondicionar la legislación a los cambios sociales que impactaron en el renovado Modelo de Justicia. La reforma no abarcó todo el contenido normativo, por lo que continuaron vigentes ambos ordenamientos, situación que complejizó el trámite de requerimiento por el órgano.

La siguiente reestructuración tendría lugar en 1981 con la entrada en vigor DecretoLey No. 47, que reduce el término a 90 días para establecer la reclamación ante órgano gestor. Esta modificación obedece, y así se consigna en el segundo POR CUANTO del documento aludido; a restaurar la confianza en la Institución tras insatisfacciones generadas por su deficiente gestión (Decreto-Ley No. 47,1981, p.1) 2 .

De lo antes mencionado se entiende que hay dos articulos en el cuerpo legal, que ilustran el grado concursal de normas, por el que transita el Caja de Resarcimientos en la actualidad.

En primer término, el art. 7 del cuerpo normativo ilustra sobre la elevada tasa impositiva que impone el órgano gestor a las víctimas en su condición de acreedores. Este arancel genera incomodidad e incentiva el desinterés de los ciudadanos en personarse a hacer efectiva la responsabilidad civil. Ello obedece a la imposibilidad de satisifacer la totalidad de la deuda debido a la aplicación de un impuesto en cada cuota de pago, aún mayor que la tasa impositiva por mora del diez por ciento, aplicada a los deudores (LEY No. 597, 1959, p. 2).

\footnotetext{
${ }^{2}$ La Ley No. 597 de 1959 mantuvo la misma semántica de la normativa anterior en el art. 4 donde se consigna el período habilitado ejercitar el derecho de cobrar en la caja de resarcimientos que es 180 días (nuevo glosario) siguientes a la firmeza de la sentencia. Este período fue nuevamente modificado Decreto-Ley No. 47,1981 por razones de viabilidad, e introduce como nota distintiva que el término comenzaría a correr a partir de la notificación de la sentencia.
}

Justicia Vol. 24 No. 36: pp. 177-195. julio - diciembre, 2019. DOI: 10.17081/just.24.36.3764 
Artículo 7: A cada uno de los pagos que deba efectuar la Caja de Resarcimientos en cumplimiento de lo que se ordena en el artículo anterior, se le descontará un veinte por ciento que engrosará los fondos de la Caja para el pago de responsabilidades civiles. Se exceptúan los pagos por concepto de plazos vencidos de pensiones, que se abonarán íntegramente si lo recaudado fuere suficiente.

La otra cuestión que genera descontento, tiene que ver con la dilación en el proceso de pago. Aún cuando se redujo el término para ejecutar el servicio de pago de 180 a 90 días, todavía resulta un trámite farragoso que ni siquiera asegura la compensación (Decreto-Ley Ni. 47, 1981).

Artículo 4.- La persona que en virtud de sentencia firme tuviere derecho a cobrar alguna cantidad por concepto de indemnización de los perjuicios o de reparación de los daños materiales, deberá reclamar dicho pago mediante escrito presentado a la Caja de Resarcimiento dentro del término de noventa días naturales, contados a partir de la fecha en que le haya sido notificada la sentencia.

Estas deficiencias han conllevado en la actualidad a que la Caja de Resarcimientos continúe realizando pagos pendientes del año 2007, debido a su insolvencia y dependencia exclusiva de los deudores (Castro, 2016).

Ante la ineficiente gestión del órgano receptor, desde el año 2015 comenzaron a tramitarse diligencias con los deudores para hacer efectivo el pago, logrando abonar la totalidad de su compromiso alrededor de 13000 ciudadanos sancionados; mientras otra cantidad más representativa (55000) quedaron pendiente de completar su deuda. Otro tanto ocurre, con los ciudadanos se encuentran privados de libertad y sujetos responsabilidad civil, de los cuales el cincuenta y cinco por ciento no han podido ser ubicados laboralmente, por lo que resulta imposible satisfacer el pago de los acreedores ni siquiera en una porción de la deuda (Castro, 2016).

Lo referido demuestra que la legislación vigente es inoperante y poco apegada a la realidad social, por lo que se requiere de otros instrumentos jurídicos que coadyuven a atender, en su real magnitud, la afectación sufrida por los perjudicados. Ello le abre espacio a la mediación penal, una vía con herramientas comunicativas eficaces que permiten satisfacer los diversos grados de la afectación recibida por las víctimas.

\section{LOS CRITERIOS DE OPORTUNIDAD Y SU APLICACIÓN EN LA LEGISLACIÓN CUBANA}

El principio de oportunidad adquiere relevancia dentro del Sistema Penal acusatorio ante la imposibilidad del aparato estatal de enjuiciar con prontitud y eficiencia, todos los hechos delictivos. Surge la necesidad de aplicar la selectividad en la judicialización promoviendo la flexibilización en la procuración de justicia y de esa manera optimizar la función jurisdiccional. Ello no desestima la regencia del principio de legalidad dentro del ordenamiento jurídico, y habilita un espacio de coexistencia entre ambos postulados que 
permite al Estado orientar su política criminal, y canalizar los recursos disponibles a las conductas más graves.

Desde esa perspectiva, el acusador público tendrá un rol preponderante para disponer bajo determinadas pautas, la no persecución del hecho contra bienes jurídicos que el interés público no estime prioritarios, con independencia de que se haya acreditado la existencia de un hecho punible contra un autor determinado (Gimeno, 2006).

En otras palabras; esta potestad devela la posibilidad de abstenerse de conocer en los casos en que se determine que no existe un interés para perseguir determinada conducta delictiva (Sánchez, 2016, pág 401).

Por ello, reviste una importancia crucial que el Ministerio Público cuente con un margen de discrecionalidad según criterios de conveniencia sobre la persecución y sostén de la acusación. Ello propiciaría la oxigenación del aparato judicial en función de la eficiencia en la impartición de justicia, y, en consecuencia, una mayor intervención de la ciudadanía en la solución del conflicto penal (Silva, 2012, pág 165).

El Sistema de Justicia Penal cubano contempla varios instrumentos jurídicos que prevén la aplicación de criterios de oportunidad en su configuración legal. Como nota distintiva, y a diferencia de otros países, la mayor incidencia de estos fundamentos recaen en la legislación sustantiva bajo la modalidad reglada. La propia normativa define los requisitos esenciales para prescindir de la persecución penal, con la imposición de una sanción pecuniara por vía administrativa, priorizando la reparación del daño (Naranjo Gómez, Alonso Betancourt, Pérez, \& Carlos, 2018, p.6).

La Ley No.88 de 1999 "De protección a la Independencia nacional y la economía de Cuba", constituye un referente importante en este sentido, tomando en cuenta que por primera vez se consigna en un texto penal el principio de oportunidad, en su literalidad, y en correspondencia con el ejercicio de la acción penal por la Fiscalía (Hernández, 2017, p.466).

Otro cuerpo legal que cumple el mismo cometido, es la Ley No 93 contra actos de Terrorismo de fecha 24 de diciembre del 2001, y que en su configuración(art.5), estipula las categorias de sujetos intervinientes en el hecho delicitvo que pueden ser objeto de aplicación criterios de oportunidad (Hernández, 2017, p.467).

Empero, la normativa que ha derivado mayor objeto de análisis por el sector académico, sobre todo lo referente a la naturaleza, extensión, y aplicación de los criterios oportunidad es el Decreto Ley 310 modificativo del Código Penal y la Ley de Procedimiento Penal de fecha 29 de Mayo del 2013.

El cuerpo legal ratifica los postulados ya vigentes con anterioridad con la promulgación de Decreto-Ley 175 de 17 de junio de 1997, emitido por el Consejo de Estado; y, como aspecto novedoso amplía el rango de potestad discrecional del órgano policial y de la Fiscalía, lo que obliga a reforzar el control de legalidad en todos los casos analizados. (Fernández, 2014, p. 382).

Justicia Vol. 24 No. 36: pp. 177-195. julio - diciembre, 2019. DOI: 10.17081/just.24.36.3764 
La reciente reformulación permite extender de la misma manera, la selectividad en el juzgamiento disminuyendo el control punitivo estatal al mínimo indispensable:

Artículo 1. Se modifica el apartado 3 del artículo 8 del Código Penal, que queda redactado de la forma siguiente: 3 . En aquellos delitos en los que el límite máximo de la sanción aplicable no exceda de tres años de privación de libertad o multa de hasta mil cuotas o ambas, la autoridad actuante está facultada para, en lugar de remitir el conocimiento del hecho al Tribunal, imponer al infractor una multa administrativa, siempre que en la comisión del hecho se evidencie escasa peligrosidad social, tanto por las condiciones personales del infractor como por las características y consecuencias del delito. Para la aplicación de esta prerrogativa a los delitos sancionables de uno a tres años de privación de libertad, se requiere la aprobación del Fiscal.

Otro aspecto novedoso en esta legislación es la incorporación del requerimiento del pago de la responsabilidad civil, como condicionante para la extinción de la responsabilidad penal. Los términos y extensión de la compensación estipulada no comprenden la intervención o consulta con la víctima, por lo que sigue resultando excluyente su aplicación.

En opinión de Hernández (2017) las peculiaridades que ofrece hoy la norma sustantiva de la isla, en cuanto a otorgarle a la autoridad policial algunas atribuciones discresionales relacionadas con la derivación que eran exclusivas de la Fiscalía, no contituyen auténticas manisfestaciones del Principio de oportunidad debido a que desnaturaliza los fundamentos teóricos de la Institución. Agrega la autora que el diseño jurídico que rige en legislación nacional no encuentra precedente en otros ordenamientos ${ }^{3}$.

Sin embargo, en opinión de los redactores del artículo, la dualidad en el ejercicio discrecional ha sido emplazada más bien para viabilizar la diligencia mencionada, sin que ello altere los postulados teóricos del principio estudiado, tomando en cuenta que el ejercicio de la acción penal continúa en poder absoluto del Ministerio Público, que le legitima para vetar las decisiones que puedan adoptar los agentes de la Institución Policial.

Los criterios de oportunidad comprenden un acotado margen de discresionalidad que los hace ocupar espacios de interés del legislador en razón de la política criminal implementada (Islas de González, 2015, p.112).

De ahí que, el ejercicio de la acción penal constituya un atributo inseparable de la procuración de justicia, que alcanza un rango utilitario hacia acciones de derivación,

${ }^{3}$ Sobre la facultad otorgada a las autoridades a las policiales para imponer sanciones pecuniarias en lugar de poner el hecho en conocimiento del Tribunal, hay que referir que la Instrucción 7 de fecha 28 de enero de 1999, emitida por el Fiscal General especifica con claridad que la Fiscalía ejerce un control estricto sobre los expedientes de la fase investigativa y es órgano facultado autorizar o aplicar las sanciones administrativas, lo que otorga el control total de la etapa indagatoria.

Justicia Vol. 24 No. 36: pp. 177-195. julio - diciembre, 2019. DOI: 10.17081/just.24.36.3764 
aprobación y ratificación. Todas ellas integran un único pilar de discrecionalidad que sólo la Ley reconoce a la Fiscalía.

Es lógico entender que puedan delegarse algunas funciones ejecutivas de la Fiscalía al órgano policial a fin de coadyuvar a la persecución penal; pero ello no implica un compromiso delegable de potestades inherentes al ejercicio del cargo.

$Y$ en respaldo al criterio anterior, la Ley rituaria le reconoce al propio Fiscal la potestad discrecional de decidir qué acciones y diligencias se practicarán durante la fase indagatoria, así como valorar el informe remitido por el actuante y orientar nuevas indicaciones en caso de no estar conteste con el presentado.

Así mismo la propia normativa también distingue en su configuración, la relación de forma escalonada, de las funciones de la persecución penal y la intervención policial.

Artículo 106: Si la resolución del Instructor proponiendo el archivo definitivo de las actuaciones es revocada por el Fiscal se iniciará de inmediato el correspondiente expediente de fase preparatoria; si es ratificada, se procederá por el Instructor a notificarla al acusado, al denunciante, a la víctima o a su representante, comunicándole, al mismo tiempo, su derecho a recurrirla en queja.

Las modificaciones introducidas en el Decreto Ley 310 del 2013 permiten ampliar el espectro de flexibilización, en función de la selectividad en la judicialización y eficacia del servicio. No obstante, para que las nuevas medidas generen un espacio propicio hacia el reposicionamiento y satisfacción de la víctima, será determinante la progresiva instrumentación de nuevos métodos de solución de conflictos que permitan la accesibilidad y autonomía del ofendido con el propósito de lograr un mayor protagonismo y la reparación integral del daño.

\section{ENTRE ALTERNATIVAS: LA MEDIACIÓN}

La intención de incorporar dentro del Sistema de Justicia Penal, nuevas herramientas de solución del conflictos, puede genenar rechazo en quiénes aún apuestan por la justicia retributiva que preporndera el castigo proporcional.

También la inadaptación a nuevos retos debido a que lo desconocido produce tensión, puede conducir a posturas reticentes o expectantes. Por esa razón, se genera desconfianza en otras herramientas pacíficas más allá, de las vías habilitadas dentro del sistema adversarial, que han mostrado eficacia al oxigenar en alguna medida al aparato judicial.

En esta línea de pensamiento, los criterios de oportunidad cumplen un rol específico en la decantación de hechos constitutivos de delitos de bagatela y la consecuente despresurización en el juzgamiento. Ampliar configuración implicaría perder objetividad y eficacia en su instrumentación.

Cierto es que dotar al esquema jurídico tradicional con criterios de oportunidad en un escenario cohabitable con el principio de legalidad, redundaría en la disminución de 
los costos de la administración pública, además de viabilizar la celebración y consecución de los actos procesales. Sin embargo, a la postre resultaría una solución inconclusa respaldada por un único interés social de restauración del orden quebrantado, en detrimento de intervención directa de los protagonistas del conflicto.

Por su parte, los Métodos Alternos de Solución de Conflictos (MASC) se erigen como herramientas no invasivas, y creadoras de un entorno pacífico que permiten forjar soluciones creativas y más ajustadas al designio de intervinientes en el conflicto Penal. Dentro del catálogo de los MASC, la Mediación se presenta como una disciplina que integra conocimientos, teorías y uso de técnicas con una proyección multidimensional a todas las ramas del Derecho (Novel, 2015).

En el ámbito penal, la Mediación contribuye a identificar el origen del conflicto, y continuar su saneamiento mediante fórmulas auto compositivas que permiten a las partes reencontrarse y enmendar sus diferencias de manera pacífica; partiendo del del reconocimiento del acusado en el tránsito hacia la reparación del daño.

La herramienta pacífica es además una vía efectiva para reinsertar a la víctima dentro del proceso, toda vez que le permite confrontar directamente con el acusado y auxiliarse de un experto en abordaje de conflictos. Lo anterior, permite encauzar a los contendientes hacia un diálogo respetuoso que genere una solución eficaz y perdurable.

Ahora bien, la progresión hacia la mediación, aunque inicialmente tendrá en el Ministerio Público el centro de su operacionalización, deberá ampliarse, profesionalizarse e institucionalizar su servicio con el propósito de perfeccionar las habilidades comunicativas.

La admisión de la mediación como una opción más, ha de constituir un pilar flexibilizador de la rigidez del Principio de Legalidad, posibilitando que el Ministerio Público pueda tener un ámbito de discrecionalidad que coadyuvaría a fortalecer el papel de la víctima, disminuir los procesos penales, lograr una verdadera compensación o equilibrio entre las partes (Magro, Carmelo, \& Cuella, 2011, p.52).

En otras palabras la solución del conflicto desde una perspectiva no adversarial no debe ser visto como un elemento que oscurece la vía tradicional de impartición de justicia, por el contrario constituye un elemento desfibrilador, que restaura la credibilidad en la judicatura. Coincidomos con Cabello y Vázquez, (2018) en que su utilidad tributa en el empoderamiento social y desarrolla habilidades en los protagonistas del conflicto para encontrar una respuesta viable a través de la colaboración y el diálogo.

La víctima, por su parte, tendría mayor inclusión y participación en la solución del conflicto. Tiene la oportunidad de exponer sus criterios y que se conozca su interés en el proceso. Puede desistir directamente si no desea prolongar su estadía y no depende de la decisión de un órgano ajeno a ella. Además, entra en contacto directo con la decisión del proceso, donde tiene voz y voto, e interviene en la decisión que finalmente se tome.

Ahora bien, la viabilidad de la mediación tiene que ver con la gestión de intereses privados que se han visto vulnerados tras la comisión del delito, con ello nada obsta -o por lo menos, no debería- para que las partes dispongan de la materia que se encuenta 
disponible a las partes, esto es, que no afente el orden publico, por lo que tratandose de delitos del orden privado -que atente contra esos intereses- juridicamente nada impide que puedan ser ventilados por la vía de los MASC, pues finalmente lo que único que se trastoca es la posibilidad de la aplicación del castigo, frontera claramente superada con la incorporación de los criterios de oportunidad en Cuba.

Por ello, deberá centrar su objeto de acción, en un grupo de ilícitos penales que detenten escasa relevancia y peligrosidad social. De manera que una plataforma que de lege ferenda sería una plataforma inicial de aplicación de la mediación en la justicia penal cubana, es la que coincide con la ratio de ejercicio de los criterios de oportunidad, que comprende tipos penales cuyo marco sancionador no debe exceder los tres años de privación de libertad o multa de hasta mil cuotas o ambas.

En dichas tipologías delictivas es más factible un diálogo real entre los implicados, y existen condiciones de igualdad que garanticen la posibilidad de llegar a acuerdos libremente aceptados por ambas partes. Y ese es precisamente el punto que en otros sistemas jurídicos permite extinguir la acción penal, p. ej. el art. 189 in fine del Código Nacional de Procedimientos Penales mexicano, de 5 de marzo de 2014.

No obstante, la ponderación debe traer aparejada una serie de aspectos y circunstancias que integran la comisión del hecho delictivo. El análisis deberá abarcar las distintas modalidades que corporifican los tipos penales tomando en cuenta que existen algunas figuras que en su composición revisten elevada peligrosidad, pero a su vez contemplan otros ilícitos que responde a un menor grado de repercusión e impacto social (Sánchez, 2014, p.135).

En resumen las vías alternativasde solución de conflictos hoy representan la opción más eficaz para recomponer la situación de marginación que ostenta la víctima en el proceso penal cubano. Sus resultados y experiencias están presentes en diversos ordenamientos legales del continente.

\section{EL ROL DEL MINISTERIO PÚBLICO EN ORDENAMIENTO PENAL DESDE LA PERSPECTIVA DE LAS VÍAS ALTERNAS DE SOLUCIÓN DE CONFLICTOS}

La promulgación de nuevas disposiciones en correspondencia con la actualización del Modelo de Justicia en Cuba y los requerimientos emergentes de la práctica judicial, han reorientado la política criminal de la isla trazada por el Estado para lograr una mayor efectividad en la prevención y enfrentamiento al delito.

La nueva perspectiva habilitada en la plataforma jurídica de la Isla, que extienden a otros tipos penales la facultad de Ministerio Público de desistir del ejercicio de la acción penal, representa un espacio ideal para la Instrumentación de la mediación si así decidieren los intervinientes del conflicto, solucionar de manera pacífica su controversia.

Esta solución podría formalizarse mediante un acuerdo reparatorio, lo que constituye el resorte jurídico legitimante del consorsio de las partes en la solución mancomunada; y sus efectos inmediatos o diferidos permiten extinguir la acción penal (Sanchez García \& García Vazquez, 2018). 
Por otro lado, el escenario creado sería consecuente con los objetivos que rigen el funcionamiento de la Fiscalía como órgano estatal, con la función proteger a los ciudadanos en el ejercicio legítimo de sus derechos fundamentales consagrados en la Constitución de la República.

En igual sentido, fortalecería el trabajo de prevención, así como la disciplina social en virtud de la observancia de las normas jurídicas, (Ley No. 83, 1997, p.2); pues lo que debe interesar al Estado no es la aplicación del castigo penal, sino la solución del conflicto velando en todo momento por la satisfacción de los intereses de los ciudadanos implicados en el ilícito penal, la reparación del daño y el saneamiento de las relaciones entre los implicados. Lo anterior, estatuye un Derecho Penal más garantista y contribuye a desmitificar la concepción de que el Estado Social de derecho se sustenta en la estricta legalidad.

\section{CONCLUSIONES}

Como ideas conclusivas los autores consideran, que la utilización de los criterios de oportunidad tiene un impacto trascendental, pues en su virtud, es la preparación jurídica del Sistema de Justicia penal cubano a fin de incorporar la mediación y otras herramientas eficaces de solución de conflictos. Además, proscribe la idea de una reformulación total del esquema sustantivo y procesal vigente, así como su consecuente dilación y empleo de recursos. El compromiso se enmarca en el perfeccionamiento del Modelo actual, al que puedan integrarse en la Ley rituaria, nuevos postulados que le concedan preeminencia de la víctima dentro del proceso penal.

En ese sentido, la implementación de la mediación en el proceso penal cubano permitiría redimensionar y democratizar el derecho de acceso a la justicia otorgándole participación directa a los ciudadanos. El cauce legal vigente posibilita su introducción, a través del ejercicio discrecional hacia la derivación de casos dentro de la procuración de justicia.

Así mismo, podría incorporarse dentro del catálogo de preceptos procesales consignados en la Ley, un capítulo dirigido al reconocimiento de los derechos de la víctima, que bien puede reunir otras categorías (ofendido o perjudicado). Esta experiencia ya ha sido implementada en otras legislaciones foráneas con resultados muy alentadores.

En consecuencia, si se pretende reposicionar a la víctima al lugar del que nunca debió despojársele dentro del proceso penal, el presente es el momento indicado; por cuanto la legislación cubana incorpora atisbos de civilidad en función de nuevas motivaciones de diálogo y reconciliación.

\section{REFERENCIAS}

Bodes Torres, J. (1988). La detención y el aseguramiento del acusado en Cuba. (F. C. Parúas, Ed.) La Habana: Ciencias Sociales. 
Cabello-Tijerina, P. A., \& Vázquez- Gutiérrez, R. L. (Mayo de 2018). CULTURA Y EDUCACION PARA LA PAZ, una perspectiva transversal. Ciudad de México, México: tirant lo blanch.

Castro Morales, Y. (27 de Abril de 2016). Caja de Resarcimiento: aún quedan muchas cuentas pendientes. Granma. La Habana, Cuba.

Fernández Romo, R. (15 de Diciembre de 2014). Las Modificaciones a la Ley de Procedimiento Penal Cubana por el Decreto -Ley No 310 del 29 de Mayo del 2013. (D. Mesa, Ed.) Comentarios a las leyes penales cubanas(3), 377-404.

Gimeno Sendra, V. (20 de Diciembre de e 2006). El Principio de Oportunidad y el M.F. Recuperado el 20 de Diciembre de 2018, de https://www.Fiscal.es: https://www.Fiscal.es/Fiscal/PA_WebApp_SGNTJ_NFIS/descarga/Comunicacio n\%20\%20Gimeno\%20Sendra\%20Vicente\%20.pdf?idFile=fa89e13f-c94d-4012$87 \mathrm{~b} 8-81 \mathrm{f} 89 \mathrm{e} 9 \mathrm{c} 4849$

Goite Pierre, M., \& Méndez López, M. (2014). La responsabilidad civil derivada del delito en Cuba: una Institución entre dos normas. En A. Medina Cuenca, Comentarios a las leyes penales cubanas. Serie ciencias penales y criminológicas (Vol. 3, págs. 294-376). La Habana: UNIJURIS.

Gómez Pérez, A. (2010). Aspectos puntuales de la victimología. Recuperado el 12 de Septiembre de 2018, de eumed.net: www.eumed.net/libros.../Aspectos\%20puntuales\%20sobre\%20la\%20Victimolo gia.htm

Hernández Rodríguez, R. d. (2017). El principio de oportunidad. Fundamentos para su inserción en Cuba. En A. Mantecón Ramos, \& E. Moya Linares, ABOGACÍA Y DERECHO: Gestión de Conflictos Jurídicos (págs. 454-473). Cuba, Cuba: ONBC.

Instrucción 7 de 1999. (28 de Enero de 1999). Fiscalía General de la República. La Habana.

Islas de González Mariscal, O. (2015). Criterios de Oportunidad. Recuperado el 4 de Diciembre de 2018, de archivos.juridicas.unam.mx: https://archivos.juridicas.unam.mx/www/bjv/libros/9/4032/12.pdf

Magro, V., Carmelo, H., \& Cuella, J. P. (2011). MEDIACIÓN PENAL. Una visión prática desde dentro hacia afuera. Alicante, España: Club Aniversario.

Naranjo, Gómez., V, Alonso Betancourt, F.d., M \& Carlos, J.( 25 de Junio del 2018). El principio de oportunidad: una experiencia cubana. Revista Jurídica Piélagus, Vol.17(Núm.1)

Novel Martí, G. (2015). La Transdisciplinariedad y Multidimensionalidad de la Ciencia de la Mediación. En F. Gorjón, \& P. Jorge, La ciencia de la Mediación. (págs. 149170). Ciudad de México: Tirant lo Blanch.

Rivero García, D. (2010). TEMAS PERMANENTES DEL DERECHO PROCESAL Y EL DERECHO PENAL. La Habana, Cuba: ONBC. 
Rivero García, D. (2012). LEY DE PROCEDIMIENTO PENAL. Disposiciones del Consejo de Gobierno del Tribunal Supremo Popular. Segunda Edición. La Habana, La Habana, Cuba: ONBC.

Rivero García, D. (2014). Estudios sobre el Proceso Penal. La Habana, Cuba: ONBC.

Rivero García, D., \& Bertot Yero, M. C. (2017). CODIGO PENAL DE LA REPÚBLICA DE CUBA. LEY NO. 62/87 (Tercera Edición ed.). La Habana: ONBC.

Rojas Jiménez, A., \& Pérez Pérez, M.(2012). La negociación como forma de solución de conflictos en el proceso penal cubano: Algunos apuntes para su inclusión. En A. Mantecón Ramos, \& C.Trujillo Hernández, ABOGACÍA Y DERECHO: Gestión de Conflictos Jurídicos( Vol.IV, págs. 52-68). La Habana, Cuba: ONBC.

Sanchez García, A. (2014). Catalogo de Delitos Mediables. Breve referencia a la utilidad social del acuerdo de mediación penal a partir del contenido patrimonial. En $\mathrm{f}$. J. Gorjón Gómez, G. Martiñon Cano, A. Sanchez García, \& Z. H. José, Mediación Penal y Justicia Restaurativa. (págs. 92-115). Ciudad de Mexico: Tirant lo Blanch.

Sánchez García, A., \& García Vázquez, B. (2018). Valor de los acuerdos reparatorios y del acuerdo de mediación(civil y familiar). En f. J. Gómez, \& r. C. Ríos, manual de mediación penal, civil, familiar y justicia restaurativa. Para mediadores, facilitadores e Instructores. Guía Practica para capacitación y Certificación. (págs. 199-216). Ciudad de México, México: tirant lo blanch.

Silva Silva, J. A. (2012). Derecho Procesal Penal (Segunda Edición ed.). Mexico D.F, México: OXFORD University Press.

Valdés Machín, E. (3 de Mayo de 2018). Caja de Resarcimiento: ¿pagar o no pagar?, ¿es esa la cuestión? AGENCIA CUBANA DE NOTICIAS. La Habana, La Habana, Cuba.

Código de Defensa Social. (1969). La Habana: Dirección Política FAR.

Constitución de la República de Cuba. (16 de julio de 2002). Gaceta Oficial de la República de Cuba(No. 10), Extraordinaria. La Habana, La Habana, Cuba: Ministerio de Justicia.

Decreto Ley 310 modificativo del Código Penal y la Ley de Procedimiento Penal. (25 de JUNIO de 2013). Gaceta Oficial de la República de Cuba(18), Extraordinaria, 132, La Habana, Cuba: Ministerio de Justicia.

Decreto-Ley No. 47, de 1ro de septiembre de 1981. (1 de Septiembre de 1981). Gaceta Oficial de la República de Cuba(29), Extraordinaria. La Habana, La Habana, Cuba.

Ley 83. Ley de la Fiscalía General de la República. (11 de Julio de 1997). Recuperado el 27 de Noviembre de 2018, de www.parlamentocubano.cu: 
http://www.parlamentocubano.cu/index.php/documento/ley-de-la-Fiscaliageneral-de-la-republica/

Ley de Enjuiciamiento Criminal . (14 de septiembre de 1882). Obtenido de www.fmyv.es: www.fmyv.es/ci/es/Ss/11.pdf

Ley de los Tribunales Militares. (1979). La Habana: ORBE.

Ley No 62. (1987). Gaceta Oficial de la República Cuba. La Habana, Cuba: Ministerio de Justicia.

Ley No. 21 Código Penal. (15 de FEBRERO de 1979). Recuperado el 2 de DICIEMBRE de 2018, de files.sld.cu/: http://files.sld.cu/prevemi/files/2013/03/ley_21_codigo_penal_19791.pdf

LEY No. 597 DE 7 de octubre de 1959. (13 de Octubre de 1959). Gaceta Oficial de la Repúblicade Cuba, Tomo Quincenal(XIX), Edición Extraordinaria, 2. La Habana, La Habana, Cuba.

Ley No. 83 de la Fiscalía General de la República. (2008). Gaceta oficial de la República Cuba. La Habana, Cuba: Ministerio de Justicia.

Ley No.6. Ley Procesal Penal Militar. (Julio de 1977). Recuperado el 2 de Diciembre de 2018, de www.parlamentocubano.cu: http://www.parlamentocubano.cu/wpcontent/uploads/2016/05/LEY-NO.-6-DE-PROCEDIMIENTO-PENAL-MILITAR.pdf 